The BDJ News section accepts items that include general news, latest research and diary events that interest our readers. Press releases or articles may be edited, and should include a colour photograph if possible. Please direct your correspondence to the News Editor, Arveen Bajaj at the BDJ, 64 Wimpole Street WIG 8YS or by email to bdj@bda.org

\section{Running for water}

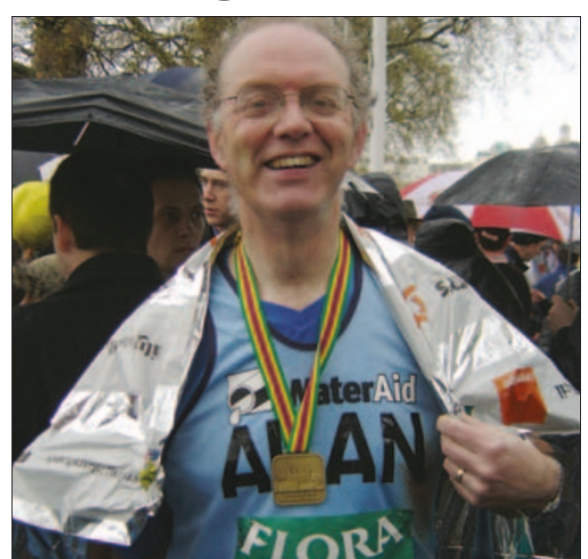

Leeds GDP and BDJ referee Dr Alan Stanley, 51, completed his first Flora London Marathon in a time of five hours and three minutes. He raised enough money for the charity Water Aid to supply clean drinking water for 100 people for every mile of the course.

\section{Trainees represented}

Dr Catherine Williams has been elected to represent flexible trainees on the BMA Junior Doctors' committee (JDC).

A specialist registrar (fixed term appointment flexible trainee) in paediatric dentistry at Bart's and the London, Dr Willams was elected by flexible trainees at a forum earlier this year. The JDC looks after all matters affecting doctors and dentists in the training grades.

It does this by promoting the interests of junior doctors, improving the quality of their working lives and seeking to influence the direction of the medical profession as a whole. It represents all junior doctors, whether or not they are members of the British Medical Association.

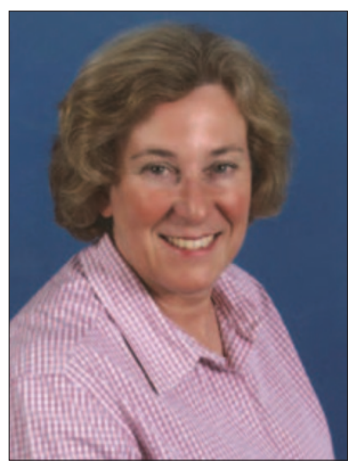

\section{Education award winners}

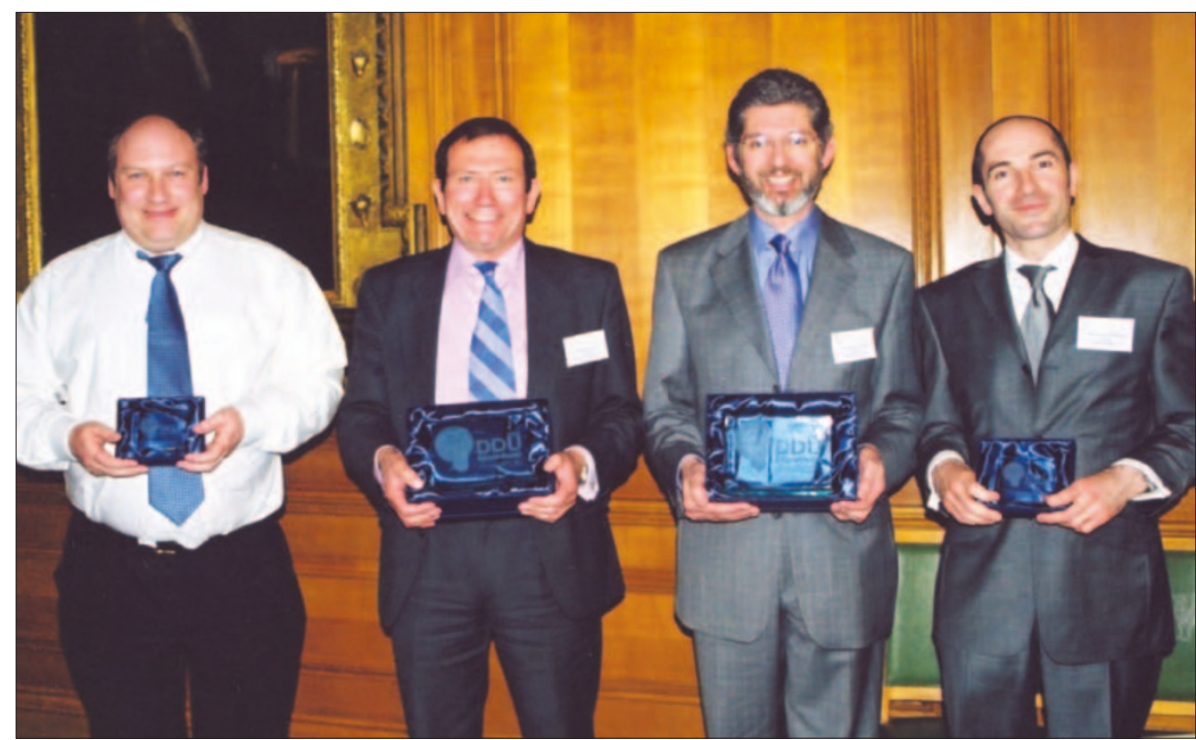

Dental teacher Peter Ash from the University of Wales College of Medicine and Martyn Green, a VT course adviser from the South Western Deanery (Taunton scheme), were the winners of this year's Dental Defence Union (DDU) Educational Awards. They received the awards for commitment and dedication to their students and VDPs and their commitment to innovation in education. Each of the finalists received an award, certificate and $£ 250$. The winner's dental school each received a donation of $£ 500$ towards the cost of educational material. Above left to right: finalist Paul Franklin, winners Peter Ash and Martyn Green and finalist Jason Stokes.

\section{Odontology prize awarded}

Major Ewen Mccoll of the Defence Dental Agency recently won the Royal Society of Medicine's Section of Odontology Presidents Prize.

The prize, which is awarded annually, is open to clinicians at various stages of training who have qualified less than twelve years prior to the meeting.

The prize is awarded for either the best clinical case presentation or best research presentation.

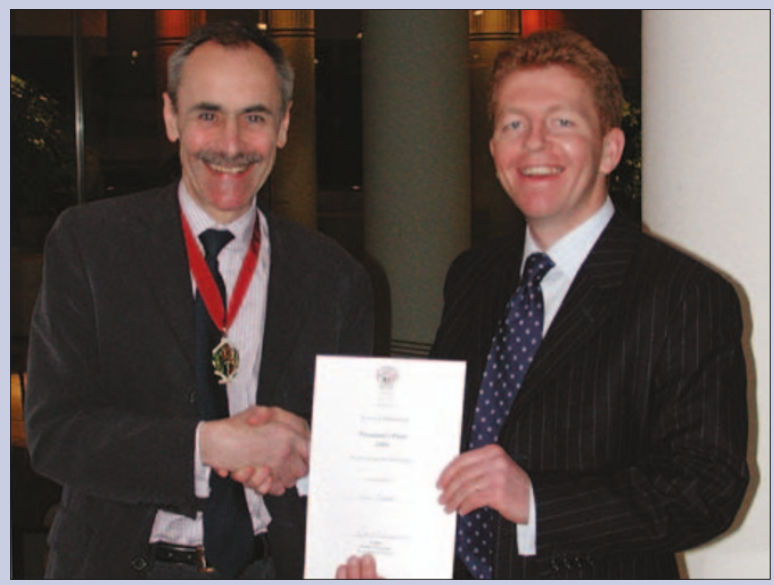

As well as the certifi- Gerald Feaver.

cate the winner in each

category receives a cheque for $£ 100$ and Young Fellow membership of the society. 


\section{DIARY}

May 2004

1st Odontological Mega Event

Date: 20-22.05.04

Venue: Lima, Peru

Contact: Hannah Parker

Tel: (511) 2428095

Fax: (511) 2340122

Email: event2@cycexpoeventos.com

www.cycexpoeventos.com

Defence Dental Agency Clinical Day

Date: 21.05 .04

Venue: JSCSC Officers' Mess,

Shrivenham

Contact: Captain Paul Leighton

Tel: +44 (0) 1296656407

Email:dda-ppcc@defence.mod.uk

Working in the UK

Date: 21.05 .04

Venue: London

Contact: Kath Blackler, Events Office

Tel: +44 (0) 2075634590

Email: events@bda.org

The Challenge of Craniofacial Pain

Date: 21-22.05.04

Venue: Royal College of Physicians

Contact: BSSCMD

Tel: +44 (0) 800371652

Clinical Innovations Conference

Date: 28-29.05.04

Venue: Royal College of Surgeons

Contact: Lisa Casey

Tel: +44 (0) 78436861

Email: lisa@smile-on.com

www.clinicalinnovations.co.uk

\section{GDC meeting update}

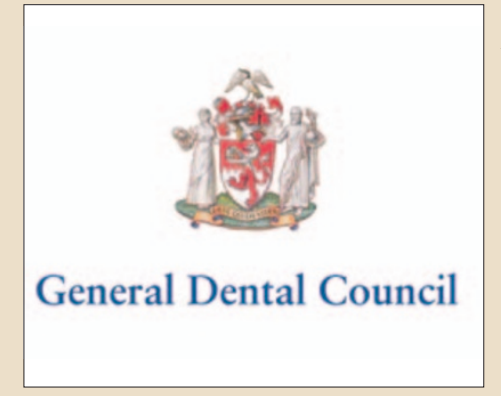

A number of decisions were made at the GDC's recent Council meeting in March.

These included a revised code of conduct for members, which covers the individual (rather than collective) accountability of members and stakeholders when carrying out duties on behalf of the Council.

The guidelines cover issues such as confidentiality, dealing with the media, personal behaviour and conflicts of interest.

With regards to public participation in meetings, there will be a fifteen minute question and answer session preceding each Council meeting. This will begin with the next meeting which is in June. The aim of the session, which is being introduced on a trial basis, is to give members of the public an opportunity to find out more about the issues on the agenda for each meeting.

Proposals are also being drawn up for a series of public roadshow-style events across the UK from next year. These will give members of the public and dental professionals across the United Kingdom a chance to hear more about, and get involved in, the Council's work.

In terms of the private patient complaints working group report, the GDC noted that the option to integrate the Non-NHS Patient Complaints scheme with the NHS schemes had been investigated but was not practicable in the short term. This will continue to be explored.

Implementation of the Council's scheme will now proceed and it agreed that the implementation plan should be reviewed by the working group when the Director is appointed.

Following a visit to the BSc Oral Health Sciences at the University of Manchester, the Council approved the recommendation of the visitors that the BSc Oral Health Sciences programme at the University be deemed sufficient for registration in dental hygiene and dental therapy.

The Council also approved the GDC Code of Conduct Complaints Procedure that had been drawn up to consider complaints or information which allege or imply a breach of the Code of Conduct for Members. This procedure could only be brought fully into force following legislative changes which are expected early next year.

The Finance and Human Resources Committee will consider the option of providing indemnity cover for all Council members should a suitable insurance product be available.

It agreed that its meetings in 2005 would take place on Thursday 10 March, Wednesday 8 June, Tuesday 6 September and Wednesday 7 December. 


\section{0th practice recognised}

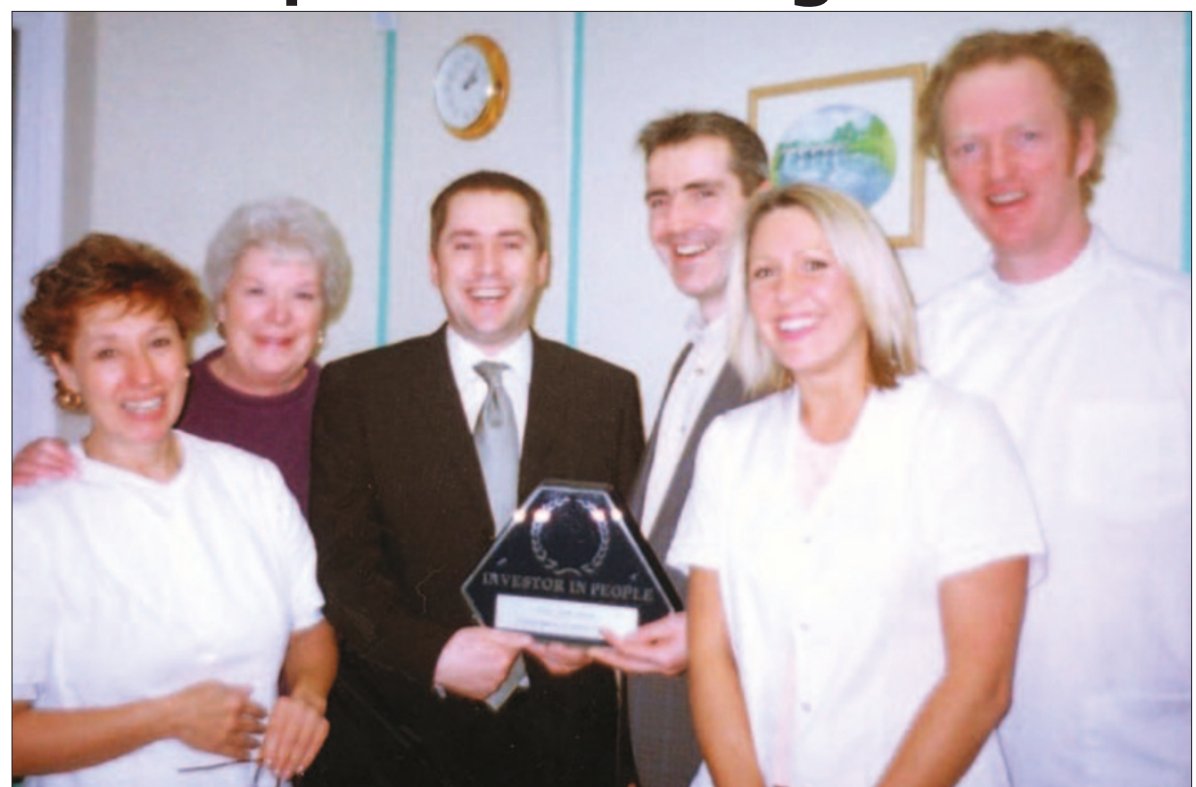

Horton Dental Practice in Surrey recently became the 200th dental practice to achieve Investor in People status through management and training consultancy company UMD Professional. The company uses Investor in People recognition as a business development tool, which can be achieved either through a oneto-one approach or through its workshop programmes. Above: Ed Jay from UMD Professional (third from left) with lan Broderick (third from right) and team at Horton Dental Practice.

\section{British Professors join American leadership institute}

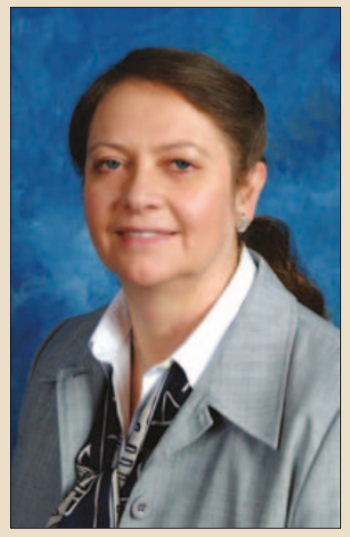

Dr Joan Kowolik

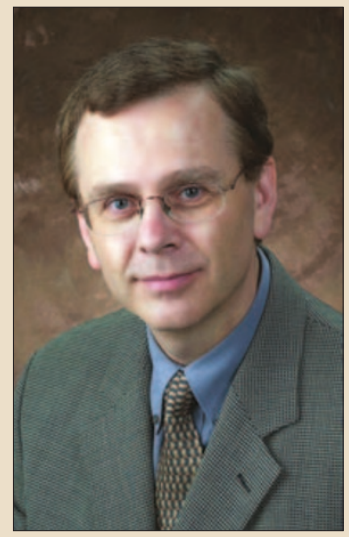

Dr Martin Thornhill

Dr Martin Thornhill and Dr Joan Kowolik were announced as the first two British graduates to become Fellows of the American Dental Education Association (ADEA) Leadership Institute at the ADEA annual meeting in Seattle.

The Leadership Institute is an intensive year long program designed to equip the most promising dental academics to become the

future leaders of dental and higher education. The four-phase Institute includes self-assessment, peer assessment, in-depth leadership development, team building, analysis of issues critical to dental and higher education, development of administrative competencies and a policy research project on an issue critical to higher education.

Each year up to twenty-one Fellows are selected to participate and Drs Thornhill and Kowolik join a group of 69 individuals to have graduated from the programme, many of whom have gone on to become Deans or hold other leadership positions within dental and higher education.

Dr Thornhill is a graduate of Kings and followed an academic career in oral medicine in the UK. He moved to the United States two years ago to Chair the Department of Dental Diagnostic Sciences at the University of Texas Health Sciences Center San Antonio.

Dr Kowolik is an Edinburgh graduate and now works as an Associate Professor in the Division of Pediatric Dentistry at the Indiana University School of Dentistry, Indianapolis. 